\title{
KALAM COSMOLOGICAL ARGUMENT AND THE MODERN SCIENCE
}

\author{
Enis DOKO \\ Dr. Öğr. Üy., İbn Haldun Ü. \\ enis.doko@ihu.edu.tr \\ https://orcid.org/0000-0001-9021-6021
}

\begin{abstract}
Huduth argument (in contemporary Western philosophy known as Kalam Cosmological argument) is an argument for the existence of God which rests on the idea that the universe has a beginning in time. Some theists have claimed that modern science, particularly modern cosmology and second law of thermodynamics supports the key premise of the argument which argues that universe began to exist. On the other hand, some atheists have claimed that Quantum Mechanics have demonstrated that particles can be created without cause falsifying the causal principle of the Kalam cosmological argument which states that everything that begins to exist has a cause. In this article we will evaluate these claims and try to determine what modern science has to say about this argument developed by medieval Muslim theologians.
\end{abstract}

Key words: Huduth argument, Kalam cosmological argument, Existence of God, Big Bang Theory, Quantum Mechanics, Second Law of Thermodynamics

\section{KELÂM'IN KOZMOLOJIKK ARGÜMANI VE MODERN BİLIM}

\section{Öz}

Hudus delili (Günümüz batı felsefesinde Kelam'ın kozmolojik kanıtı olarak da bilinir) Tanrı'nın varlığı lehinde geliştirilmiş, evrenin zamanda bir başlangıcı olduğu fikrine dayanan bir delildir. Bazı teistler modern bilimin, özellikle modern kozmoloji ve termodinamiğinin ikinci yasasının argümanın kilit öncülü olan evrenin zamanda bir başlangıcı olduğu iddiasını desteklediğini iddia etmişlerdir. Diğer taraftan bazı ateistler Kuantum Mekaniğinin parçacıkların nedensiz olarak yaratılabileceğini gösterdiğini, bunun da başlangıcı olan her șeyin bir nedeni olduğunu ifade eden Hudus delilinin nedensellik öncülünü yanlışladığını iddia etmişlerdir. Bu makaledeki amacımız bu iddiaları değerlendirip, modern bilimin Müslüman kelamcılar tarafından geliştirilen bu delil hakkında ne söylediğini belirlemektir.

Anahtar kelimeler: Hudus delili, Kelam'ın kozmolojik argümanı, Tanrı'nın varlığı, Büyük Patlama Kuramı, Kuantum Mekaniği, Termodinamiğin İkinci Yasası

Atıf: Doko, Enis. "Kalam Cosmological Argument and the Modern Science". Kader 16/1 (Haziran 2018): $1-13$.

Geliş Tarihi: 21.04.2018 Kabul Tarihi: 29.06.2018 Doi: 10.18317/kaderdergi.417640




\section{Introduction}

Cosmological argument is a type of argument for the existence of God. Its history can be traced back to the writings of Plato and Aristotle. It was probably the most popular argument in Islamic tradition, defended by Al-Kindi, Al-Ghazali, Al-Farabi, Ibn Sina, Ibn Rushd etc. All the cosmological arguments share the following form:

1. There is something of type $X$.

2. Due to $Y, X$ requires cause/explanation.

3. Due to $Z$, the chain of causes/explanations must terminate at some first cause.

4. This first cause shares some unique properties with God; therefore can be identified as God.

$\mathrm{X}$ is an object, phenomenon or proposition which requires explanation or causation. It is the focus of the argument. Different cosmological arguments have different foci: Motion, change, existence of contingent beings ${ }^{1}$, truth of true contingent propositions, contingent beings' persistence etc. $\mathrm{Y}$ is the causal principle or some kind of Principle of sufficient reason. It is a general principle which is used to show that $\mathrm{X}$ requires cause or explanation. Examples of $\mathrm{Y}$ are following principles: For every true contingent proposition there is sufficient explanation why it is true rather than false; every contingently existing being, requires some outside cause which caused it to exist; motion/change requires cause; everything that began to exist has a cause etc. $Z$ is the reason supplied to deduce that chain of causes cannot be infinite, or even if it is infinite it is not sufficient to explain/cause $Y$, hence there must be a first cause.

Cosmological argument is not only an argument based on some out of date medieval principles, in fact there are several contemporary versions of it still defended today. Probably most famous of these arguments is Kalam cosmological argument, which can be traced back to 'Ilm al-Kalām, from where it gets its name. Historically it has been defended by John Philoponus, Al-Kindi, Al-Ghazali, Saadia ben Gaon, Bonaventure, John Locke etc ${ }^{2}$. The argument was resurrected by William Lane Craig3, who modernized and defended the argument. Besides Craig the argument has been defended by contemporary Western philosophers Mark Nowacki ${ }^{4}$, Stuart

Beings whose existence is not necessary.

W.L. Craig, The Kalām Cosmological Argument. (London: The Macmillan Press, 1979), 1-50.

W.L. Craig, The Kalām Cosmological Argument. (London: The Macmillan Press, 1979); W.L. Craig and J. D. Sinclair, 'The Kalām Cosmological Argument', in W. L. Craig and J. P. Moreland (eds.), The Blackwell Companion to Natural Theology. (London: Blackwell, 2009) 101-201.

$4 \quad$ M.Nowacki, The Kalām Cosmological Argument for God. (New York: Barnes and Noble, 2007). 
Hackett ${ }^{5}$, Robert Koons ${ }^{6}$ and David Oderberg 7 . Argument has also been studied by many contemporary Muslim thinkers. ${ }^{8}$

The focus $(X)$ of Kalam cosmological argument is the universe, more specifically beginning of the universe to exist. Having such intuitive focus is one of the big advantages of the argument. While concepts such as contingency are abstract and difficult to understand by lay people, beginning to exist is very familiar concept and can be grasped by anyone. The causal principle $(\mathrm{Y})$ of the Kalam cosmological argument is "Everything that begins to exist has a cause". This causal principle is weaker compared to the classical causal principles such as the Leibnitz's Principle of sufficient reason that every true proposition must have sufficient reason for why it is true rather than false, or the Causal Principle which states that every contingent being must have some explanation for its existence. Since this principle is weaker and makes less assumptions, the person who denies these principles can nevertheless accept the Kalam cosmological argument's causal principle which is immune to the problems faced by those principles. This is another advantage of the Kalam cosmological argument. The first cause in Kalam cosmological argument is usually reached $(Z)$ by either denying the possibility of the actual infinite or defending the thesis that a collection formed by successive addition cannot be an actual infinite. One particularly attractive feature of this argument is its concordance with Quran's claim that God created everything out of nothing (Al-An'am 6/101). Thus, a successful Kalam cosmological besides providing an evidential support for theism, it also confirms one of the most basic claim of Quran, i.e. universe have a finite past.

Using above guidelines, Kalam cosmological argument can be presented in the following form:

1. The universe began to exist.

2. Everything that begins to exist has a cause.

3. Therefore, the universe has a cause. (From 1 and 2)

4. If the universe has a cause, that cause is God. ${ }^{9}$

\footnotetext{
S. Hackett, The Resurrection of Theism. (Chicago: Moody Press, 1957).

R. C. Koons, 'A New Kalam Argument: Revenge of the Grim Reaper' Noûs, 48 no.2 (2014): 256-267

D. S. Oderberg, 'Traversal of the Infinite, the 'Big Bang,'and the Kalam Cosmological argument', Philosophia Christi, 4 no.2 (2002): 305-344.

8 For some examle see: U. M. Kılavuz, Kelâm'da kozmolojik delil. (İstanbul: İz yayıncılık,2009); M. Bulğen, 'Continuous Re-Creation: From Kalam Atomism to Contemporary Cosmology', Kalam Journal, 1 no.1 (2018); R. Acar, 'Büyük Patlama Teorisi Kelâm Kozmoloji Argümanını Destekler mi?', Sakarya Üniversitesi İlahiyat Fakültesi Dergisi, no.14 (2006); E. Doko, 'Bilfiil sonsuzun imkansızlı̆̆ına dayanmayan yeni bir Hudus delili savunması', Felsefe Tartışmaları, no.54 (2017): 61-79.

$9 \quad$ Following Ghazali Craig usually presents the argument as: "1. Everything that begins to exist has a cause. 2. The universe began to exist. 3 . Therefore universe has a cause. ". Of course, in this form argument is incomplete. In order to have a successful argument, we must also show that the cause of the universe is God.
} 


\section{God exists. (From 3 and 4 )}

A sound (successful) argument is an argument which is logically valid, and its premises must be more plausible than their denials. Above argument is obviously logically valid, if we deny the conclusion we must deny at least one of the premises. Therefore, in order to have sound argument, one must defend three claims: That universe began to exit, the beginning of the universe was caused, and the cause of the universe is God. If one can show that these three claims are more likely to be true compared to their denials we have a successful argument.

In support of the first premise, the claim that universe has finite past, Craig gives two philosophical arguments as well as two scientific confirmations ${ }^{10}$. The first argument is the philosophical argument based on the impossibility of actual infinite. Craig formulates the argument as follows:

1. An actual infinite cannot exist.

2. An infinite temporal regress of events is an actual infinite.

3. Therefore, an infinite temporal regress of events cannot exist. ${ }^{11}$

Second argument is a philosophical argument based on impossibility of formation of actual infinite by successive addition. This argument can be expressed as follows:

1. A collection formed by successive addition cannot be an actual infinite.

2. The temporal series of events is a collection formed by successive addition.

3. Therefore, the temporal series of events cannot be an actual infinite. ${ }^{12}$

The third argument is based on the claim that Big bang theory provides a scientific confirmation to the claim that universe began to exist. The fourth argument is based on the second law of thermodynamics and claims that this law too provides a scientific confirmation of the claim that universe began to exist. ${ }^{13}$

In this paper we are not going to be concerned with the philosophical arguments formulated in support of the first premise. Rather we will try to evaluate Craig's

W.L. Craig, The Kalām Cosmological Argument. (London: The Macmillan Press, 1979).

W.L. Craig and J. D. Sinclair, 'The Kalām Cosmological Argument', in W. L. Craig and J. P. Moreland (eds.), The Blackwell Companion to Natural Theology. (London: Blackwell, 2009) 103

12 W.L. Craig and J. D. Sinclair, 'The Kalām Cosmological Argument', in W. L. Craig and J. P. Moreland (eds.), The Blackwell Companion to Natural Theology. (London: Blackwell, 2009) 117.

13 We should note that traditional Kalam argument is based on The A-theory of time also known as tensed theory of time. According to A-theory of time, past, present and future are mind independent properties of time. In this view future does not exist. The flow or passage of time is objective feature of reality. If flow of time is illusion, than the past, present and future events exist all together, time is like space. Even if we can show that the past is finite, still the second premise cannot be justified. In tensless theories of time, universe is tenslessly existing 4 dimensional block. Finitude of past simply means that, the space-time block has an edge.. For defense of A-theory of time as well as critique of tensless B-theory of time see: W. L. Craig, The Tensed Theory of Time: A Critical Examination, (Dordrecht: Kluwer Academic Publishers, 2000); W. L. Craig, The Tenseless Theory of Time: A Critical Examination, (Dordrecht: Kluwer Academic Publishers, 2000) 
claim that modern Cosmology and the second law of thermodynamics provide evidential support to the first premise of Kalam cosmological argument. Thus, we will evaluate the claim that modern science supports the first premise of the Kalam cosmological argument. We will argue that cosmology has demonstrated that observable universe is not immutable and is evolving, a result which seems to suggest that universe must have finite past and the Standard Model in cosmology known as $\Lambda \mathrm{CDM}$ model predicts that universe has a beginning in time. We also argued that while second law of thermodynamics and the fact that universe is not in thermal equilibrium is compatible with the eternal universe, given the Boltzmann Brain problem it seems to suggest that with high probability universe has a beginning in time.

In case of the second premise, the causal principle which states that everything began to exist has a cause for its existence, some philosophers have claimed that Quantum Mechanics have demonstrated that this premise is false ${ }^{14}$. We will also try to evaluate this claim as well. We will argue that the wave function collapse is not uncaused event and virtual particles are excitations of the quantum fields, they do not come uncaused from nothing. Therefore Quantum Mechanics does not give us good counter examples against the second premise of the Kalam cosmological argument.

\section{Cosmology and the Beginning of the Universe}

Physical Cosmology is a scientific discipline, which studies the origin, evolution, and fate of the universe. Since cosmology is the scientific discipline directly interested to the origin of the universe, the most natural question which comes to mind is what modern cosmology has to say about the question of the age of the universe. Does it exist eternally, or did it begin to exist? The answer seems to be the observable universe almost certainly and the universe in general probably began to exist.

Modern cosmology is dominated by the so called Big Bang theory, or more specifically the $\Lambda \mathrm{CDM}$ model also known as Standard model of cosmology. This model is based on General Theory of relativity and provides very accurate description of several important properties of the universe: Hubble's law and the expansion of the universe, the existence and structure of the cosmic microwave background radiation, the abundance of light elements (Hydrogen, Deuterium, Helium, Lithium), the large scale structure of the universe, the existence of the baryon acoustic oscillation etc. ${ }^{15}$ Empirical observations have clearly shown that universe is evolving and past universe is different than its current state. For example distant galaxies appear very different from nearby galaxies, given that light travels with finite speed, distant galaxies show the past state of the universe. ${ }^{16}$ In 2011

14 G. Oppy, 'Professor William Craig's Criticisms of Critiques of Kalam Cosmological Arguments by Paul Davies, Stephen Hawking, and Adolf Grunbaum', Faith and Philosophy, 12, no. 2 (1994): 237250.

15 For detailed review see: V. Mukhanov, Physical Foundations of Cosmology. (Cambridge: Cambridge University Press, 2005).

16 E. Bertschinger, 'Simulations of Structure Formation in the Universe', Annual Review of Astronomy and Astrophysics 36 no.1 (1998): 599-654 
astronomers observed structures which have no elements heavier than hydrogen and helium formed just minutes after the big bang ${ }^{17}$, providing direct confirmation of the claim that all the heavy elements are formed in the stars and are existing for finite amount of time. Thus, we can safely say that it is an empirical fact that observed universe is evolving and we do not live in immutable universe. This picture is in perfect accord with universe existing for finite time. If this successful Big Bang model is extrapolated to the early universe it predicts what our first premise claims that universe began to exist. Hence Big Bang model seems to confirm the first premise of the Kalam cosmological argument.

To counter this argument two strategies are used. First approach is to point some alternative cosmological model to Big Bang model, usually models which seem to involve eternal past. Space does not permit us to review all the alternative models, such comprehensive review has been done by Craig and Sinclair, interested reader is referred to their work ${ }^{18}$. They conclude that most of the alternatives also involve beginning and others have problems and involve incredible fine tunings. The important point to note is that neither of the alternatives is empirically better than the Big Bang model, neither of them is widely accepted by the community of cosmologist. Nearly all the alternatives involve speculative non-verified physics. Hence, we should take the predictions of the verified Big Bang model more seriously than its speculative alternatives.

Another important point to note is infinite can have different meanings in physics. For example, in statistical thermodynamics, phase transitions are defined inside a container with infinite volume. No physicist will claim that therefore kettle must be infinitely big to observe water turning to steam. Infinite in thermodynamics simply is interpreted as very big rather than literal infinite. Hence constructing successful cosmological models which involves universe with infinite age, does not necessarily imply that universe is eternal. Like in statistical thermodynamics, this infinite can also be interpreted as very big.

Second strategy is to point out the fact that we lack unification of Quantum Theory and General Relativity. Big Bang Model is based solely on General Relativity. It is usually claimed that in the Planck era, which is the first $10^{-43}$ seconds after the Big Bang, quantum effects become important; this era should be described by Quantum Gravity. Unfortunately we do not have complete theory of Quantum Gravity. The objectors usually claim that since we do not have theory of Quantum Gravity, it is possible that there was some pre-Big bang era. Perhaps Quantum Gravity will show that universe is eternal. Is this a successful objection?

Promissory note is not an argument. It is correct that Quantum Gravity may surprise us and show that there is pre-Big Bang era (that's why we claimed cosmology shows probably universe began to exist). But we have no good reason to assume that General

17 M. Fumagalli, J. M. O'Meara, J. X. Prochaska, 'Detection of Pristine Gas Two Billion Years After the Big Bang'. Science 334 no. 6060 (2011): 1245-9.

18 W.L. Craig and J. D. Sinclair, 'The Kaläm Cosmological Argument', in W. L. Craig and J. P. Moreland (eds.), The Blackwell Companion to Natural Theology. (London: Blackwell, 2009) 125-182 
Relativity's prediction that universe is not eternal, will turn out to be false. There is no feature in Quantum Physics which implies that universe must be eternal, so why should we assume that its unification with General Relativity will lead to eternal universe? Thus, this speculative claim does not undermine the argument, unless there is some good reason which shows that Quantum Mechanics will change the story.

Second line of evidence from cosmology for the beginning of the universe comes from the so-called singularity theorems. As we noted above Classical Big Bang model predicts that there is an initial singularity at the first instants of our universe. One may think that this singularity is a theoretical artifact, rather than real physical entity. But the work pioneered by Penrose and Hawking showed that singularities seem to be intrinsic to General Theory of relativity. There are several different singularity theorems whose Hawking-Penrose singularity theorem based on the strong energy condition and Penrose's singularity theorem based on null energy condition are the most famous ones ${ }^{19}$. The strong energy condition is too strong and requires antigravity due to tension to be smaller than gravity. This is violated by the cosmological constant today; hence it is not a good argument in support of the beginning of the universe. Latter theorem is more interesting, because null energy condition is weaker and can be satisfied by most of the classical theories. But it too has two important weaknesses; first if the theorem is to work space must be infinite, an assumption whose truth is unknown. Secondly the null energy condition is violated by the Quantum fields ${ }^{20}$; hence one may expect that this assumption fails at the early stages of the universe where quantum effects become important. Of course, if Penrose's null energy singularity theorem fails, it does not mean that universe is eternal, it simply means that theorem cannot be used as an argument in support of the finite past. However, the work of theoretical physicist Aron Wall ${ }^{21}$, suggest that Penrose's theorem, with the assumption that generalized second law of thermodynamics holds, may be valid even in Quantum Gravity situations. Wall uses semi-classical analysis, where quantum mechanical corrections are assumed to be small and are taken into account and shows that the singularity theorem holds in such scenario. He also gives arguments, claiming that most probably the theorem will hold even in the case where quantum fluctuations are large. If Aron Wall's arguments are correct, then singularity theorems should also apply for Quantum Gravity theories.

There is a third theorem which seems to support that universe had a beginning in time, the so called Kinematic Incompleteness Theorem, or Borde, Guth and Vilenkin (BVG) theorem. This theorem states that a space-time which on average is expanding (the average Hubble constant is positive), is past geodesically incomplete. In simple

19 S. W. Hawking and G.F.R. Ellis, The large scale structure of space-time. (Cambridge: Cambridge University Press, 1973).

20 L. Ford, 'Negative Energy Densities in Quantum Field Theory', International Journal of Modern Physics A A25, no. 2355 (2010).

21 A. Wall, 'The Generalized Second Law implies a Quantum Singularity Theorem', Class. Quantum Grav. 30, no.165003 (2013). 
terms such universe must have finite past. The advantage of this theorem is that it does not relay on any energy condition, it does not even assume the truth of General Relativity. Hence, we can say that it is a very powerful theorem which provides pretty strong evidence in support of finite past of the universe. Many models including the eternal inflationary model are subject to this theorem. Of course, this does not constitute decisive proof of the finitude of the past, since one can develop models which have on average larger or equal contracting periods compared to the expanding period. George Ellis' model of emergent universe is example of such model. ${ }^{22}$ While this model is not subject to BVG, nevertheless it cannot be stable when Quantum effects are taken in to account, hence cannot be past eternal. ${ }^{23}$ Another alternative which can violate BVG theorem is to use some cyclic universe model. While some versions of these models can bypass the BVG theorem, second law of thermodynamics does not allow them to be past eternal. ${ }^{24}$ Neil Turok and Paul Steinhardt's cyclic model can bypass this thermodynamic problem, but this model involves more expansion then contraction and therefore is subject to BVG theorem..$^{25}$ Thus given the lack of any empirical evidence of long contracting period, as well as speculative nature and problems faced by the models which are not subject to BVG theorem, we can say that BVG theorem provides compelling evidence in support of the first premise of the Kalam cosmological argument.

\section{Second Law Of Thermodynamics And The Beginning Of The Universe}

One of the most important quantities in thermodynamics is entropy. Entropy is the measure of disorder. More technically entropy is the logarithm of number of accessible microscopic states of the system ${ }^{26}$. In other words, entropy is number measuring the total number of possible ways the atoms can be arranged in an object. According to the Second Law of Thermodynamics, entropy of a closed system increases or remains constant. If the entropy remains constant, system has maximum entropy and we say that system is in equilibrium ${ }^{27}$. Universe is a giant closed system; therefore, second law can be applied to our universe too. Universe clearly is not in equilibrium, total entropy of the universe by far is smaller than the maximal entropy state. Entropy continues to increase with time. Second law of thermodynamics combined with the fact that our universe is not in equilibrium seems to imply that our universe exists for a finite amount of time. Because if the universe was eternal, it would have already reached the equilibrium. Therefore, it seems that Second law of thermodynamics combined with the observation that universe is in low entropy

22 G. Ellis, J. Murugan, and C. Tsagas, 'The Emergent Universe: An Explicit Construction', Classical and Quantum Gravity 21 (2004): 233-50

23 A. Mithani and A. Vilenkin, 'Instability of an Emergent Universe', Journal of Cosmology and Astroparticle Physics 1405 (2014).

24 R. C. Tolman, Relativity, Thermodynamics, and Cosmology, (New York: Dover, 1987).

25 P. Steinhardt and N. Turok, 'A Cyclic Model of the Universe" Science 296 (2002): 1,436-39

$26 S=k_{B} \ln (\Omega)$, here $S$ denotes entropy, $k_{B}$ is the Boltzman's constant, and $\Omega$ is the number of accessible microstates of the system.

27 For technical, yet accessible introduction to entropy: H. Kroemer and C. Kittel, Thermal Physics. (W. H. Freeman Company,1980) 27-55. 
state verifies the claim that universe began to exist.

There are several objections to this argument. The most frequent objection is to point out the fact that Second Law of thermodynamics is statistical rather than exact law of nature. Entropy in average increases, but nevertheless it can sometimes decrease. Usually systems became more disordered, but nevertheless rarely random thermal fluctuations may create more ordered systems. Now if the universe is eternal and reached the equilibrium sometime in the far past, it will not remain forever in this state. Obviously after staying long time in this maximal entropy state, eventually its entropy will decrease due to thermal fluctuations, and some ordered subsystems will emerge. Perhaps our universe is just one such thermal fluctuation. All the low entropy (order) is result of that thermal fluctuation. Given infinite amount of time such fluctuation is expected.

Is this objection successful? I think not. While this objection correctly demonstrates that second law is compatible with eternal universe, it does not undermine the argument. Assuming that our ordered visible universe is result of thermal fluctuation of eternal universe leads to so called Boltzmann brain paradox. The probability of galaxy popping out as a thermal fluctuation is extremely higher than billions of galaxies popping out as a thermal fluctuation. Because entropy of latter will be much lower. The probability of just single star popping out randomly is unimaginably higher compared to single galaxy forming as a thermal fluctuation. Emergence of brain is more probable compared to single star. Obviously, single brain with false memory and perception popping out as thermal fluctuation, is astronomically more probable, than low entropy universe with billion galaxies like ours. Such brains are called Boltzmann Brains. It is perfectly possible that we are Boltzmann brains rather that normal human beings. How likely is that we are Boltzmann brains with fake memory and perception rather than normal human beings? If the universe exists for finite amount of time and we have not reached the equilibrium, it is very unlikely that we are Boltzmann brains. But if we live in eternal universe, then we almost certainly are Boltzmann brains, given the odds of emergence of our universe compared to Boltzmann brains. Therefore, if we assume that we are ordinary observers rather than Boltzmann brains, we most probably live in universe with finite past rather than thermal fluctuation. Hence the thermal fluctuations objection cannot undermine the fact that given second law of Thermodynamics our universe with very high probability began to exist.

There is one more way to respond this argument; one can build models such that in past the universe were at low entropy conditions at some middle time rather than beginning of the time. Call this time t. According to these models, when we move in both directions, past and future of this time $t$ entropy decreases.

We should note that these models lack any empirical support. Secondly, the fact that entropy was low at time $t$ is left as a brute fact (of course one may claim that universe having low entropy beginning is as mysterious as having at time t.). But even if we assume that this proposal is correct, still it does not show that universe did not began to exist. Beginning of the universe can be defined in a geometrical or 
thermodynamical sense. While these models will lack geometric beginning, if we identify the arrow of time with the increase of entropy (which is commonly done) then we can say that the universe has thermodynamic beginning at time $\mathrm{t}^{28}$ and time flows in two different directions.

To sum up, second law of thermodynamics combined, with the observation that universe is not in thermal equilibrium, while logically compatible with the existence of eternal universe, seems to suggest that with high probability universe exist for finite amount of time. Hence second law of thermodynamics seems to provide evidential support for the first premise, since in light of this law the truth of first premise seems to be more likely than its denial.

\section{Quantum Mechanics and the Causality Principle}

The most common objection to the causality principle is based on Quantum Mechanics ${ }^{29}$. According to defenders of this objection, in quantum mechanics we have many uncaused events which result from indeterministic nature of the theory. Even we can talk about particle's coming to exist uncaused. Hence quantum mechanics provides clear counter example to the second premise.

How successful is this objection? First not everyone agrees with the claim that Quantum Mechanics is an indeterministic theory. This is so if we assume the orthodox Copenhagen interpretation. But there are alternative deterministic interpretations of Quantum Mechanics such as Bohm-De Broglie pilot wave interpretation which is empirically equivalent to Copenhagen interpretation. But even if we assume the standard Copenhagen interpretation of Quantum Mechanics, still it does not follow that quantum events lack cause. Unpredictability, does not imply no causation. In Quantum Mechanics causes does not necessitate their effects, but nevertheless all the effects have a cause. In quantum mechanics the behavior of the particles is determined by the Schrödinger (Dirac for relativistic particles) equation. This equation evolves deterministically. Indeterminism comes into play when some physical property of the particle is measured. Measurement results in what physicist call a wave function collapse. There are several (or perhaps many depending on the quantity measured) possible outcomes of this measurement. The possible outcomes and the probability of each these outcomes are determined by the Schrödinger equation. While there is finite probability associated with each of these outcomes, which one will come out is not determined by anything. This is the indeterminism involved in the quantum mechanics. Schrödinger equation basically depends on the potential and interactions the particle is subjected to. Hence outcomes and their probabilities are determined by environment (potential) as well as particle's interaction with other particles. Hence the indeterministic result of our measurement is not completely random it depends on many physical factors, such as the potential and the interaction with other particles. Hence outcomes are caused

28 A. Wall, 'The Generalized Second Law implies a Quantum Singularity Theorem', Class. Quantum Grav. 30, no.165003 (2013).

29 Oppy, 'Professor William Craig's Criticisms of Critiques of Kalam Cosmological Arguments by Paul Davies, Stephen Hawking, and Adolf Grunbaum',. 
by these factors, they are not uncaused. If the potential was different or we had different interactions, then the outcome would have been different. Thus, even in Quantum Mechanics, events are caused, although the cause does not determine its effect. While this analysis is also valid for particles which come out of vacuum, we should also note that vacuum in Quantum Mechanics is not nothing. It is a physical state, which has energy and many properties. In fact, these particles are manifestation of quantum field's excitation from ground state, which normally is unnoticeable, to the excited state. Thus, particles are excitations of the quantum fields, they do not come uncaused from nothing. Thus, quantum mechanics does not constitute a counter example to the second premise.

\section{Conclusion}

In this paper we analyzed the claims that Modern Cosmology and Second Law of Thermodynamics support the first premise of the Kalam cosmological argument which states that universe began to exist. We argued that cosmology has demonstrated that observable universe is not immutable and is evolving, a result which seems to suggest that universe must have finite past. Standard Model in cosmology known as $\Lambda$ CDM model which is based on General Theory of Relativity predicts that universe has a beginning in time. There seems to be no reason to assume that this result will fail when we will have fully Quantum Mechanical theory of Gravity. In fact the work of theoretical physicist Aron Wall suggest that Penrose's theorem which predicts that universe began to exist, with the assumption that generalized second law of thermodynamics holds, may be valid even in Quantum Gravity situations. Than we argued that while second law of thermodynamics combined, with the observation that universe is not in thermal equilibrium is compatible with the eternal universe, given the Boltzmann Brain problem it seems to suggest that with high probability universe exist for finite amount of time. Lastly, we examined the claim that Quantum Mechanics allows emergence of particles without cause falsifying the causal premise of the Kalam cosmological argument. We argued that wave function collapse is not uncaused, and the particles which emerge from vacuum are excitations of the quantum fields, they do not come uncaused from nothing. Hence Quantum Mechanics does not give us good counter examples against the second premise of the Kalam cosmological argument. Thus it seems modern science provides evidential support to the Kalam cosmological argument by supporting the first premise of the argument via cosmology and the second law of thermodynamics.

\section{References}

Acar, R., 'Büyük Patlama Teorisi Kelâm Kozmoloji Argümanını Destekler mi?', Sakarya Üniversitesi İlahiyat Fakültesi Dergisi no.14 (2006).

Bertschinger, E.,'Simulations of Structure Formation in the Universe', Annual Review of Astronomy and Astrophysics 36 no.1 (1998): 599-654. 
Bulğen, M., 'Continuous Re-Creation: From Kalam Atomism to Contemporary Cosmology', Kalam Journal, 1 no.1 (2018).

Craig, W. L., The Kalām Cosmological Argument, London: The Macmillan Press, 1979.

Craig, W. L. and Sinclair, J. D. ,'The Kalām Cosmological Argument', in W. L. Craig and J. P. Moreland (eds.), The Blackwell Companion to Natural Theology, London: Blackwell, 2009, 101-201.

Craig, W. L., The Tensed Theory of Time: A Critical Examination, Dordrecht: Kluwer Academic Publishers, 2000.

Craig, W. L., The Tenseless Theory of Time: A Critical Examination, Dordrecht: Kluwer Academic Publishers, 2000.

Doko, E., ‘Bilfiil sonsuzun imkansızlığına dayanmayan yeni bir Hudus delili savunması', Felsefe Tartışmaları, no.54 (2017): 61-79.

G. Ellis,G.; Murugan, J. and Tsagas, C., 'The Emergent Universe: An Explicit Construction', Classical and Quantum Gravity 21 (2004): 233-50.

Ford, L., 'Negative Energy Densities in Quantum Field Theory', International Journal of Modern Physics A A25, no. 2355 (2010).

Fumagalli, M., O'Meara, J. M., Prochaska, J. X., 'Detection of Pristine Gas Two Billion Years After the Big Bang'. Science 334 no. 6060 (2011): 1245-9.

Hackett, S. The Resurraction of Theism, Chicago: Moody Press, 1957.

Hawking, S. W., and Ellis, G.F.R, The large scale structure of space-time, Cambridge: Cambridge University Press, 1973.

Koons, R. C. , 'A New Kalam Argument: Revenge of the Grim Reaper' Noûs, 48 no.2 (2014): 256-267

Nowacki, M., The Kalām Cosmological Argument for God, New York: Barnes and Noble, 2007.

Oderberg, D. S., 'Traversal of the Infinite, the 'Big Bang,'and the Kalam Cosmological argument', Philosophia Christi, 4 no.2 (2002): 305-344.

Oppy, G., 'Professor William Craig's Criticisms of Critiques of Kalam Cosmological Arguments by Paul Davies, Stephen Hawking, and Adolf Grunbaum', Faith and Philosophy, 12, no. 2 (1994): 237-250.

Kroemer, H. and Kittel, C., Thermal Physics, W. H. Freeman Company, 1980. 
Kılavuz, U. M., Kelâm'da kozmolojik delil, İstanbul: İz yayıncılık, 2009.

Mithani, A. and Vilenkin, A., 'Instability of an Emergent Universe', Journal of Cosmology and Astroparticle Physics 1405, 2014.

Mukhanov, V., Physical Foundations of Cosmology, Cambridge: Cambridge University Press, 2005.

Steinhardt, P. and Turok, N., 'A Cyclic Model of the Universe" Science 296 no.1 (2002): 436-39

Tolman, R. C., Relativity, Thermodynamics, and Cosmology, New York: Dover, 1987.

Wall, A., 'The Generalized Second Law implies a Quantum Singularity Theorem', Class. Quantum Grav. 30, no.165003 (2013). 